\title{
Targeting the immune-suppressive tumor microenvironment to potentiate CAR T cell therapy
}

\author{
Tiffany C. Y. Tang ${ }^{1}$, Ning Xu ${ }^{1,2}$ and Alla Dolnikov ${ }^{1,2 *}$ \\ ${ }^{1}$ Children's Cancer Institute, University of New South Wales, Sydney, Australia \\ ${ }^{2}$ Kids Cancer Center, Sydney Children's Hospital, Sydney, Australia
}

\begin{abstract}
Chimeric antigen receptor (CAR) T cell therapy is a promising new immunotherapy that reprograms patient $\mathrm{T}$ lymphocytes to specifically recognize and kill tumor cells. CAR T cell therapy has produced some dramatic responses in acute lymphoblastic leukemia and lymphomas, but responses have been less spectacular in solid tumors. To make CAR T cell therapy effective for solid tumors, CAR T cells must overcome an immune-suppressive tumor microenvironment (TME) that attenuates CAR T cell function. This review provides insights into mechanisms of CAR T cell therapy resistance with respect to the TME and offers strategies for improving CAR T cell therapy by targeting immune-suppressive factors in tumors.
\end{abstract}

\section{Chimeric antigen receptor (CAR) $\mathrm{T}$ cell therapy}

CAR $\mathrm{T}$ cell therapy is a promising new immunotherapy that provides potential curative treatments for cancer. CARs consist of a tumor-targeting monoclonal antibody-derived single chain variable fragment $(\mathrm{scFv})$ fused to a $\mathrm{T}$ cell receptor-derived cytoplasmic signaling domain $\mathrm{CD} 3 \zeta$ and one or more domains derived from costimulatory $\mathrm{T}$ cell receptors CD28, 4-1BB, or OX40 (Figure 1A) [1]. When expressed by $\mathrm{T}$ cells, CARs redirect $\mathrm{T}$ cell specificity to antigens expressed on cancer cells. To deliver CAR $\mathrm{T}$ cell therapy, patient $\mathrm{T}$ cells are genetically modified to express CAR and then amplified $e x$ vivo to numbers suitable for adoptive cell therapy [2]. Recent clinical data provided strong evidence that $\mathrm{T}$ cells from patients with $\mathrm{B}$ cell malignancies can successfully be redirected to initiate an effective anti-tumor response even at advanced stages of the disease [3-15]. In relapsed or refractory B cell acute lymphoblastic leukemia (B-ALL) and certain types of lymphoma, this strategy has led to dramatic complete responses in more than $80 \%$ of patients treated with CD19-targeting (CAR19) T cell therapies [3-15]. The FDA has recently approved the CAR $\mathrm{T}$ cell products axicabtagene ciloleucel and tisagenlecleucel to treat relapsed or refractory B-ALL and diffuse large B cell lymphoma (DLBCL) $[8,12,16,17]$. CAR T cells can thus be considered as "designer drugs" that are personalized to patients' needs and manufactured to clinical standards.

Using viral vectors to transfer CAR genes to $\mathrm{T}$ cells requires complex protocols that are time-consuming and expensive. Compared to viral vectors, non-viral transposon-based gene delivery systems offer a simpler and cheaper alternative for CAR T manufacture with no infectious potential [18-20]. Novel CAR T cells generated using Sleeping Beauty (SB) and PiggyBac (PB) transposon/transposase systems have demonstrated strong efficacy against leukemia cells in preclinical mouse models [18-21]. This preclinical data provided the basis for testing transposon-based CAR $\mathrm{T}$ cells in clinical trials in USA, Australia and China [21-23]. Importantly, the decreased cost and complexity of non-viral genome modification methods can widen patient access to CAR T cell therapies by increasing the number of hospitals capable of implementing them.

\section{Mechanisms and strategies to overcome immune sup- pression in the tumor microenvironment (TME)}

Recent clinical studies have shown that CAR T cells can cure select patients with cancer, while others experience transient or no clinical benefit $[4,5,10,15,24,25]$. Short duration of remission in patients treated with CAR T cells can be associated with functional CAR T cell exhaustion in the immune-suppressive TME [6,7,26,27]. The immune-suppressive TME considerably reduces the efficacy of CAR $\mathrm{T}$ cell therapy against solid tumors such as prostate [28-30], ovarian [31-35], breast [36-39], pancreatic [40-44], and brain [45] cancers. Disialoganglioside (GD2)-targeting CARs incorporating CD28 and OX40 co-stimulatory domains showed efficient CAR T cell infiltration of neuroblastoma tumors; however, the suppression of tumor growth was marginal, suggesting that CAR T cell function is compromised by the immune-suppressive TME $[46,47]$.

The immune-suppressive TME is enriched with regulatory immune cells such as regulatory $\mathrm{T}$ cells (Tregs) [48-55], myeloidderived suppressor cells (MDSCs) [36,39,56,57], tumor-associated macrophages (TAMs) [58-60], and cancer-associated fibroblasts (CAFs) [35,61]. These regulatory immune cells inhibit CAR T cells by releasing suppressive factors such as TGF- $\beta[28,30,58,62]$, IL-4 $[43,63,64]$, IL-10 [40], prostaglandin E2 (PGE2) [65], and immunesuppressive metabolites such as kynurenine and adenosine via indolamine-2,3-dioxygenase (IDO) $[59,66,67]$ and CD39/CD73

*Correspondence to: Alla Dolnikov, Children's Cancer Institute, University of New South Wales, Sydney, Australia, E-mail: ADolnikov@ccia.org.au

Key words: cancer, CAR T cells, tumor microenvironment

Received: March 04, 2020; Accepted: March 26, 2020 Published: March 31, 2020 

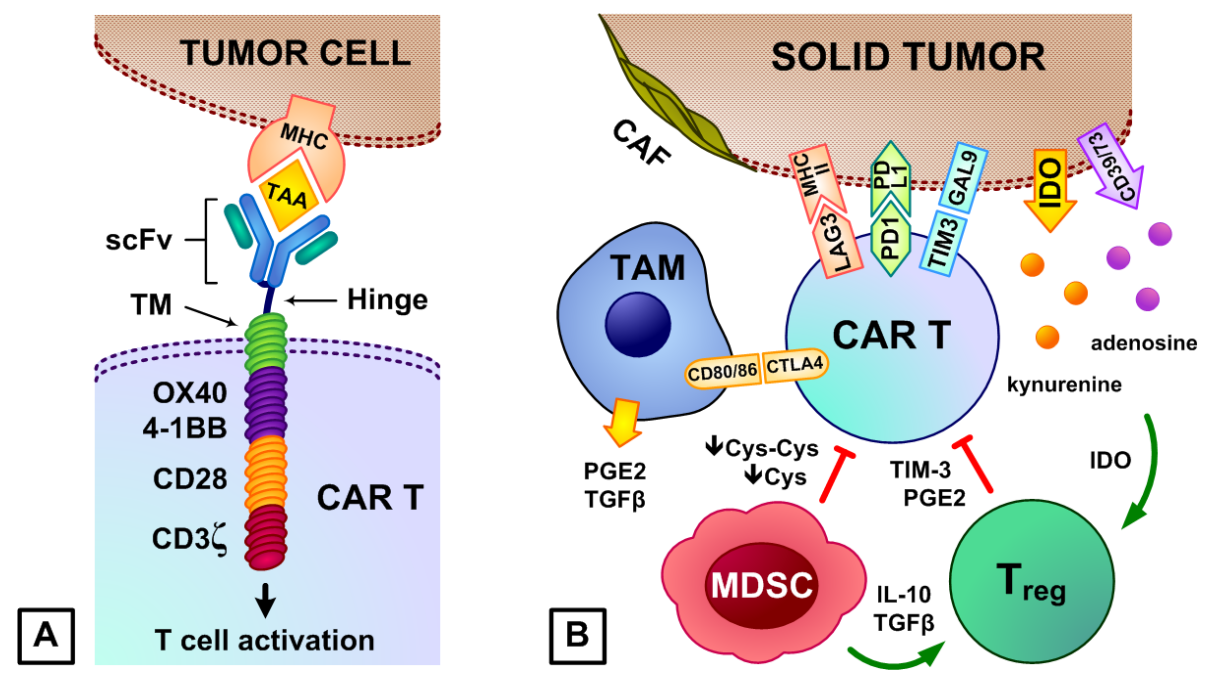

Figure 1. (A) Chimeric antigen receptor (CAR) T cells. Derived from tumor-specific monoclonal antibodies, the extracellular single chain variable fragment (scFv) recognizes tumorassociated antigens (TAA) and is connected via the hinge to the transmembrane domain (TM) that anchors to the CAR T cell's plasma membrane. Attached to the TM are intracellular costimulatory (CD28, 4-1BB, or OX40) and T cell receptor CD3 $\zeta$-derived signaling domains that activate the CAR T cell. (B) Immune-suppressive cells in the TME lower CAR T anti-tumor activity. Regulatory T cells (Tregs) inhibit CAR T cell proliferation and cytokine production via TIM-3 and prostaglandin E (PGE2). Myeloid-derived suppressor cells (MDSCs) suppress T cell activation via cystine (Cys-Cys) and cysteine (Cys) deprivation [72], and facilitate Tregs recruitment and expansion via IL-10 and TGF- $\beta$ [73]. Type II tumor-associated macrophages (TAMs) release PGE2 and TGF- $\beta$, and express CD80/CD86 that preferentially binds to the inhibitory CTLA-4 receptor in CAR T cells. Cancer-associated fibroblasts (CAFs) physically prevent CAR T cells from accessing tumor antigens. Tumor cells express MHC class II, galectin-9 (Gal9), and PD-L1 that bind to the LAG3, TIM-3, and PD-1 receptors on CAR T cells to promote CAR T cell exhaustion and apoptosis [71]. Immune-suppressive metabolites kynurenine and adenosine are produced via indolamine-2,3-dioxygenase (IDO) and CD39/CD73, and IDO is involved in activation of Tregs [74]

respectively [38,68-70]. Additionally, tumor cells often down-regulate $\mathrm{T}$ cell co-stimulatory ligands that would normally promote CAR T cell function, while up-regulating immune-suppressive ligands (MHC class II, galectin-9, PD-L1 and CD86) that activate immune checkpoints (LAG3, TIM-3, PD-1 and CTLA-4) in adoptively transferred CAR T cells (Figure 1B) [71]. Chemoresistant and chemorefractory pediatric B-ALLs exhibit significant interpatient heterogeneity in the expression of 35 genes that encode $\mathrm{T}$ cell co-stimulatory and inhibitory ligands, and in vitro models showed association of CD86, CD70, ICOSL, OX40, and IL-10 with CAR T cell expansion and exhaustion [26]. B-ALLs exhibit low expression of PD-L1 and CD80/CD86, which activates the PD-1 and CTLA-4 checkpoints in CAR T cells [26]. Unlike B-ALLs, $\mathrm{T}$ cell acute lymphoblastic leukemia (T-ALL) cells express high levels of PD-L1 and often CD80/CD86, and so can be considered as more immune-suppressive than B-ALL in this respect [26]. B-ALLs from some patients, however, express MHC class II and galectin-9 (Gal9) that bind to the LAG3 and TIM-3 receptors on CAR T cells to promote CAR T cell exhaustion and apoptosis [71].

CARs with multiple co-stimulatory domains and/or genome-edited checkpoint receptors have been engineered to mitigate the immunesuppressive TME [70,72-83]. New approaches also combine CAR T cell therapy with chemotherapeutic drugs, epigenetic modulators, or targeted drugs that attenuate immune suppression in the TME in addition to direct anti-tumor activity [32,36,45,47,48,50,67,84-89]. Some epigenetic drugs up-regulate the tumor's antigen expression for targeting by CAR $\mathrm{T}$ cells, up-regulate $\mathrm{T}$ cell co-stimulatory ligands, or induce type I interferon responses in tumors against pro-viruses integrated into target cell genomes [90]. The hypomethylating agent 5-azacitidine (AZA) sensitizes leukemia and lymphoma cells to CAR $\mathrm{T}$ cell therapy by modulating the TME in leukemia and inducing OX40L to promote CAR T cell function $[20,86]$. Other epigenetic modulators down-regulate the immune-suppressive ligands that activate specific immune checkpoints in CAR T cells. JQ1, a potent small-molecule bromodomain and extra terminal domain (BET) inhibitor, down-regulates PD-L1 expression in neuroblastoma and sensitizes neuroblastoma cells to CAR T cell therapy [47,85]. JQ1 also promotes CAR $\mathrm{T}$ cell activity by up-regulating interferon regulatory factor 7 (IRF7) signalling to activate type I interferon responses $[47,85]$.

Combining CAR T cells with specific targeted drugs have been shown to promote CAR T cell function $[67,84,87,89]$. Ibrutinib is a small-molecule drug that binds permanently to Bruton's tyrosine kinase and is used to treat chronic lymphocytic leukemia (CLL). CLL patients showed prolonged remission after combined treatment with ibrutinib and CAR19 T cells $[84,87,89]$. Ibrutinib induced mobilization of the disease into blood or bone marrow, where it is highly responsive to CAR T therapy $[84,87,89]$. Lenalidomide, another targeted drug for treating multiple myeloma (MM), delayed the onset of CAR T cell functional exhaustion in the immune-suppressive TME by potentiating CAR T cells that target B cell maturation antigens in MM [67].

Another promising strategy involves using checkpoint inhibitors to rejuvenate exhausted CAR T cells [70,75-83]. Up-regulation of specific checkpoint ligands such as PD-L1 in inflamed TME induces premature CAR T cell exhaustion. PD-1 checkpoint blockade with PD-1 and/or PD-L1 antagonistic antibodies [91-94] acts to rescue CAR T cells from exhaustion and improve their cytolytic activity in melanoma [77,9597]. PD-1 checkpoint inhibitors induced remission in B-ALL patients who relapsed following CAR T cell therapy [98], but did not promote CAR $\mathrm{T}$ cell efficacy in recent neuroblastoma clinical studies [99], suggesting that additional factors in the TME may be involved in CAR $\mathrm{T}$ cell exhaustion in neuroblastoma patients.

Agents targeting Tregs, MDSCs, TAMs, and CAFs in the TME are currently being investigated in the context of CAR T cell therapy against hematological and solid tumors [100-107]. Macrophage colony stimulating factor 1 (CSF1) and granulocyte macrophage colony stimulating factor (GM-CSF) antagonists were shown to inhibit TAMs and MDSCs and promote CAR T cell function [100-102]. 


\section{Conclusion}

CAR $\mathrm{T}$ cell therapy has been a major breakthrough in cancer treatment. Despite encouraging clinical results in certain hematological malignancies, high resistance to CAR $\mathrm{T}$ cell therapies has often been reported in patients with solid tumors. Multiple mechanisms contributing to CAR $\mathrm{T}$ resistance have led to the design of complex therapeutic strategies to avoid immune suppression in the TME of solid tumors and to increase tumor cell susceptibility to CAR T cell attack. Resistance mechanisms need to be examined in different contexts in order to design effective therapeutic combinations and improve the efficacy of CAR T cell therapy.

\section{Acknowledgments}

This work was funded by Kids Cancer Project grants. The authors thank Dr Kenneth Micklethwaite from Westmead Institute of Medical Research, Sydney, for providing constructive discussion of the manuscript.

\section{Author contributions}

All authors participated in the preparation, writing and revision of the manuscript. All authors have read and agreed to the published version of the manuscript.

\section{References}

1. Sadelain M, Brentjens R, Rivière I (2013) The basic principles of chimeric antigen receptor design. Cancer discovery 3: 388-398. [Crossref]

2. Lee DW, Barrett DM, Mackall C, Orentas R, Grupp SA (2012) The future is now: chimeric antigen receptors as new targeted therapies for childhood cancer. Clin Cancer Res 18: 2780-2790.

3. Brentjens RJ, Davila ML, Riviere I, Park J, Wang X (2013) CD19-targeted T cells rapidly induce molecular remissions in adults with chemotherapy-refractory acute lymphoblastic leukemia. Sci Transl Med 5: 177ra38.

4. Davila ML, Riviere I, Wang X, Bartido S, Park J, Curran K (2014) Efficacy and toxicity management of 19-28z CAR T cell therapy in B cell acute lymphoblastic leukemia. Sci Transl Med 6: 224ra25.

5. Gardner RA, Finney O, Annesley C, Brakke H, Summers C (2017) Intent-to-treat leukemia remission by CD19 CAR T cells of defined formulation and dose in children and young adults. Blood 129: 3322-3331.

6. Kochenderfer JN, Somerville RPT, Lu T, Shi V, Bot A (2017) Lymphoma remissions caused by Anti-CD19 chimeric antigen receptor T cells are associated with high serum Interleukin-15 Levels. J Clin Oncol 35: 1803-1813.

7. Kochenderfer JN, Somerville RPT, Lu T, Yang JC, Sherry RM (2017) Long-Duration complete remissions of diffuse large $\mathrm{b}$ cell lymphoma after Anti-CD19 chimeric antigen receptor T cell therapy. Mol Ther 25: 2245-2253.

8. Locke FL, Ghobadi A, Jacobson CA, Miklos DB, Lekakis LJ (2019) Long-term safety and activity of axicabtagene ciloleucel in refractory large B-cell lymphoma (ZUMA-1): a single-arm, multicentre, phase 1-2 trial. Lancet Oncol 20: 31-42.

9. Locke FL, Neelapu SS, Bartlett NL, Siddiqi T, Chavez JC (2017) Phase 1 Results of ZUMA-1: A Multicenter Study of KTE-C19 Anti-CD19 CAR T cell therapy in refractory aggressive lymphoma. Mol Ther 25: 285-295.

10. Maude SL, Frey N, Shaw PA, Aplenc R, Barrett DM (2014) Chimeric antigen receptor $\mathrm{T}$ cells for sustained remissions in leukemia. N Engl J Med 371: 1507-1517.

11. Maude SL, Laetsch TW, Buechner J, Rives S, Boyer M (2018) Tisagenlecleucel in children and young adults with B-Cell Lymphoblastic Leukemia. $N$ Engl J Med 378: 439-448.

12. Neelapu SS, Locke FL, Bartlett NL, Lekakis LJ (2017) Axicabtagene Ciloleucel CAR T-Cell Therapy in refractory large B-Cell Lymphoma. N Engl J Med 377: 2531-2544. [Crossref]

13. Park JH, Rivière I, Gonen M, Wang X, Sénéchal B (2019) Long-Term follow-up of CD19 CAR Therapy in Acute Lymphoblastic Leukemia. The New England Journal of Medicine 378: 449-459.
14. Turtle CJ, Hanafi LA, Berger C, Gooley TA (2016) CD19 CAR-T cells of defined CD4+:CD8+ composition in adult B cell ALL patients. J Clin Invest 126: 2123-2138.

15. Turtle CJ, Hanafi LA, Berger C, Hudecek M, Pender B (2016) Immunotherapy of nonHodgkin's lymphoma with a defined ratio of CD8+ and CD4+ CD19-specific chimeric antigen receptor-modified T cells. Sci Transl Med 8: 355ra116.

16. FDA (2017) FDA approves axicabtagene ciloleucel for large B-cell lymphoma. U.S Food \& Drug Administration.

17. FDA (2018) FDA approves tisagenlecleucel for adults with relapsed or refractory large B-cell lymphoma. U.S. Food \& Drug Administration.

18. Bishop D, Xu N, Shen S, O'Brien T (2017) Differing co-stimulatory, linker and spacer domains produce variations in CD4 and CD8 cell composition and cytotoxic potentia in CD19-specific chimeric antigen receptor (CAR19) $\mathrm{T}$ cells generated with the piggyBac transposase. Cytotherapy 19: S10.

19. Bishop DC, Xu N, Tse B, O'Brien TA, Gottlieb DJ (2018) PiggyBac-Engineered T Cells Expressing CD19-Specific CARs that Lack IgG1 Fc spacers have potent activity against B-ALL Xenografts. Mol Ther 26: 1883-1895. [Crossref]

20. Dolnikov A, Shen S, Klamer G, Joshi S, Xu N (2015) Antileukemic potency of CD19specific $\mathrm{T}$ cells against chemoresistant pediatric acute lymphoblastic leukemia. Exp Hematol 43: 1001-1014

21. Kebriaei P, Singh H, Huls MH, Figliola MJ, Bassett R (2013) Phase I trials using Sleeping Beauty to generate CD19-specific CAR T cells. The Journal of Clinical Investigation 126: 3363-3376.

22. ANZCTR (2018) A Phase I Study of CD19 Specific Chimeric Antigen Receptor T-cells for Therapy of Persistent and Relapsed B-cell Leukaemia and Lymphoma Post Allogeneic Stem Cell Transplantation (Registry ID: ACTRN12617001579381). National Health and Medical Research Council Australia.

23. ClinicalTrials.gov (2020) Anti-CD19 CAR in PiggyBac Transposon-Engineered T Cells for Relapsed/Refractory B-cell Lymphoma or B-cell Acute Lymphoblastic Leukemia (Registry ID: NCT04289220). Yan'an Affiliated Hospital of Kunming Medical University.

24. Grupp SA, Kalos M, Barrett D, Aplenc R (2013) Chimeric antigen receptor-modified T cells for acute lymphoid leukemia. N Engl J Med 368: 1509-1518.

25. Lee DW, Kochenderfer JN, Stetler-Stevenson M, Cui YK (2015) T cells expressing CD19 chimeric antigen receptors for acute lymphoblastic leukaemia in children and young adults: a phase 1 dose-escalation trial. Lancet 385: 517-528.

26. Tse B, Xu N, Bishop D, Gottlieb D (2018) Tumour microenvironment modulates cart cell fate in paediatric leukemia. Cytotherapy 20: S97.

27. Yan Z, Li L, Wang W, OuYang B, Cheng S (2019) Clinical efficacy and tumor microenvironment influence in a Dose-Escalation study of anti-CD19 Chimeric Antigen Receptor T Cells in Refractory B-Cell Non-Hodgkin's Lymphoma. Clinical Cancer Research 0101.

28. Kloss CC, Lee J, Zhang A, Chen F, Melenhorst JJ (2018) Dominant-Negative TGFbeta receptor enhances PSMA-Targeted human CAR T cell proliferation and augments prostate cancer eradication. Mol Ther 26: 1855-1866.

29. Slovin SF, Wang X, Hullings M, Arauz G, Bartido S (2013) Chimeric antigen receptor $(\mathrm{CAR}+)$ modified $\mathrm{T}$ cells targeting prostate-specific membrane antigen (PSMA) in patients (pts) with castrate metastatic prostate cancer (CMPC). Journal of Clinical Oncology 31: 72-72.

30. Zhang Q, Helfand BT, Carneiro BA, Qin W (2018) Efficacy against human prostate cancer by prostate-specific membrane antigen-specific, transforming growth factor- $\beta$; insensitive genetically targeted $\mathrm{cd} 8+\mathrm{t}$-cells derived from patients with metastatic castrate-resistant disease. European Urology 73: 648-652.

31. Kershaw MH, Westwood JA, Parker LL, Wang G, Eshhar Z (2006) A phase I study on adoptive immunotherapy using gene-modified $\mathrm{T}$ cells for ovarian cancer. Clinical Cancer Research 212: 6106-6115.

32. Parente-Pereira AC, Whilding LM, Brewig N, van der Stegen SJ (2013) Synergistic chemoimmunotherapy of epithelial ovarian cancer using erbb-retargeted $t$ cells combined with carboplatin. J Immunol 191: 2437-2445. [Crossref]

33. Wang W, Kryczek I, Dostal L, Lin H, Tan L (2016) Effector T cells abrogate stromamediated chemoresistance in ovarian cancer. Cell 165: 1092-1105.

34. Hamanishi J, Mandai M, Iwasaki M (2007) Programmed cell death 1 ligand 1 and tumor-infiltrating CD8+ T lymphocytes are prognostic factors of human ovarian cancer. Proc Natl Acad Sci US A 104: 3360-3365. 
35. Ko SY, Barengo N, Ladanyi A, Lee J-S, Marini F (2012) HOXA9 promotes ovarian cancer growth by stimulating cancer-associated fibroblasts. The Journal of clinical investigation 122: 3603-3617.

36. Alizadeh D, Trad M, Hanke NT, Larmonier CB, Janikashvili N (2014) Doxorubicin eliminates myeloid-derived suppressor cells and enhances the efficacy of adoptive T-cell transfer in breast cancer. Cancer Res 74: 104-118.

37. Domschke C, Schneeweiss A, Stefanovic S, Wallwiener M, Heil J, Rom J (2016) Cellular immune responses and immune escape mechanisms in breast cancer: Determinants of immunotherapy. Breast Care (Basel) 11; 102-107. [Crossref]

38. Stagg J, Divisekera U, McLaughlin N (2010) Anti-CD73 antibody therapy inhibits breast tumor growth and metastasis. Proceedings of the National Academy of Sciences of the United States of America 107: 1547-1552.

39. Morales JK, Kmieciak M, Knutson KL, Bear HD, Manjili MH (2010) GM-CSF is one of the main breast tumor-derived soluble factors involved in the differentiation of CD11b-Gr1- bone marrow progenitor cells into myeloid-derived suppressor cells. Breast Cancer Res Treat 123: 39-49.

40. Batchu RB, Gruzdyn OV, Mahmud EM, Chukr F, Dachepalli R (2018) Inhibition of Interleukin-10 in the tumor microenvironment can restore mesothelin chimeric antigen receptor T cell activity in pancreatic cancer in vitro. Surgery 163: 627-632.

41. Schueneman AJ, Sugar EA, Uram J, Bigelow E (2013) Low total lymphocyte count is associated with poor survival in patients with resected pancreatic adenocarcinoma receiving a GM-CSF secreting pancreatic tumor vaccine. Ann Surg Oncol 3: S725-S730.

42. Maliar A, Servais C, Waks T, Chmielewski M, Lavy R (2012) Cells that target pancreatic adenocarcinoma antigens eliminate tumors and metastases in mice. Gastroenterology 143: 1375-1384 e5.

43. Prokopchuk O, Liu Y, Henne-Bruns D, Kornmann M (2005) Interleukin-4 enhances proliferation of human pancreatic cancer cells: evidence for autocrine and paracrine actions. British Journal of Cancer 92: 921-928.

44. Varghese AM (2017) Chimeric antigen receptor (CAR) $\mathrm{T}$ and other $\mathrm{T}$ cell strategies for pancreas adenocarcinoma. Chin Clin Oncol 6: 66.

45. Neagu MR, Reardon DA (2015) An Update on the role of immunotherapy and vaccine strategies for primary brain tumors. Curr Treat Options Oncol 16: 54.

46. Chaudhry K, Shen S, Wang L, Bishop D, Micklethwaite K (2018) Imaging the dynamics of receptor-modified $\mathrm{T}$ cell effector function against leukaemia and neuroblastoma targets. Cytotherapy 20: S103.

47. Dolnikov A, Xu N, Tse B, Shen S, O'Brien T (2018) Bromodomain inhibitor JQ1 modulates immune suppressive pathways in neuroblastoma and enhances CARGD2T cell therapy. Cytotherapy 20: S97.

48. Lutsiak ME, Semnani RT, De Pascalis R, Kashmiri SV (2005) Inhibition of CD4(+)25+ $\mathrm{T}$ regulatory cell function implicated in enhanced immune response by low-dose cyclophosphamide. Blood 105: 2862-2868.

49. Heylmann D, Bauer M, Becker H (2013) Human CD4+CD25+ regulatory T cells are sensitive to low dose cyclophosphamide: implications for the immune response. PLoS One 8: e83384.

50. Traverso I, Fenoglio D, Negrini S, Parodi A, Battaglia F (2012) Cyclophosphamide inhibits the generation and function of $\mathrm{CD} 8(+)$ regulatory $\mathrm{T}$ cells. Hum Immunol 73: 207-213.

51. Ghiringhelli F, Larmonier N, Schmitt E, Parcellier A, Cathelin D (2004) CD4+CD25+ regulatory $\mathrm{T}$ cells suppress tumor immunity but are sensitive to cyclophosphamide which allows immunotherapy of established tumors to be curative. Eur J Immunol 34: 336-344.

52. Kurtulus S, Sakuishi K, Ngiow SF, Joller N (2015) TIGIT predominantly regulates the immune response via regulatory $\mathrm{T}$ cells. The Journal of Clinical Investigation 125: 4053-4062.

53. Turk MJ, Guevara-Patiño JA, Rizzuto GA, Engelhorn ME, Houghton AN (2004) Concomitant tumor immunity to a poorly immunogenic melanoma is prevented by regulatory T cells. The Journal of Experimental Medicine 200: 771-782.

54. Quezada SA, Peggs KS, Simpson TR, Shen Y (2008) Limited tumor infiltration by activated $\mathrm{T}$ effector cells restricts the therapeutic activity of regulatory $\mathrm{T}$ cell depletion against established melanoma. J Exp Med 205: 2125-2138.

55. Simpson TR, Li F, Montalvo-Ortiz W, Sepulveda MA (2013) Fc-dependent depletion of tumor-infiltrating regulatory $\mathrm{T}$ cells co-defines the efficacy of anti-CTLA-4 therapy against melanoma. J Exp Med 210: 1695-1710.
56. Dolcetti L, Peranzoni E, Ugel S, Marigo I, Fernandez Gomez A (2010) Hierarchy of immunosuppressive strength among myeloid-derived suppressor cell subsets is determined by GM-CSF. Eur J Immunol 40: 22-35.

57. Burga RA, Thorn M, Point GR, Guha P, Nguyen CT (2015) Liver myeloid-derived suppressor cells expand in response to liver metastases in mice and inhibit the antitumor efficacy of anti-CEA CAR-T. Cancer Immunol Immunother 64: 817-829.

58. Ye XZ, Xu SL, Xin YH, Yu SC, Ping YF (2012) Tumor-associated microglia/ macrophages enhance the invasion of glioma stem-like cells via TGF-betal signaling pathway. J Immunol 189: 444-453.

59. Zhao Q, Kuang DM, Wu Y, Xiao X, Li X-F (2012) Activated CD69+ T Cells foster immune privilege by regulating IDO expression in tumor-associated macrophages. The Journal of Immunology 188: 1117. [Crossref]

60. Revoltella RP, Menicagli M, Campani D (2012) Granulocyte-macrophage colonystimulating factor as an autocrine survival-growth factor in human gliomas. Cytokine 57: $347-359$.

61. Lakins MA, Ghorani E, Munir H (2018) Cancer-associated fibroblasts induce antigenspecific deletion of CD8 (+) T Cells to protect tumour cells. Nature Communications 9: $948-948$

62. Zhang Q, Yang XJ, Kundu SD, Pins M (2006) Blockade of transforming growth factor\{beta\} signaling in tumor-reactive $\mathrm{CD} 8(+) \mathrm{T}$ cells activates the antitumor immune response cycle. Mol Cancer Ther 5: 1733-1743.

63. Li Z, Jiang J, Wang Z, Zhang J, Xiao M (2008) Endogenous Interleukin-4 promotes tumor development by increasing tumor cell resistance to apoptosis. Cancer Research 68: 8687 .

64. Todaro M, Alea MP, Di Stefano AB, Cammareri P (2007) Colon cancer stem cells dictate tumor growth and resist cell death by production of interleukin-4. Cell Stem Cell 1: 389-402.

65. Mulligan JK, Rosenzweig SA, Young MR (2010) Tumor secretion of VEGF induces endothelial cells to suppress $\mathrm{T}$ cell functions through the production of PGE2. $J$ Immunother 33: 126-135.

66. Ninomiya S, Narala N, Huye L, Yagyu S, Savoldo B, Dotti G (2015) Tumor indoleamine 2,3-dioxygenase (IDO) inhibits CD19-CAR T cells and is downregulated by lymphodepleting drugs. Blood 125: 3905-3916.

67. Works M, Soni N, Hauskins C, Sierra C, Baturevych A (2019) Anti-B-cell maturation antigen chimeric antigen receptor $\mathrm{T}$ cell function against multiple myeloma is enhanced in the presence of lenalidomide. Mol Cancer Ther 18: 2246-2257.

68. Bastid J, Regairaz A, Bonnefoy N, Dejou C, Giustiniani J (2015) Inhibition of CD39 enzymatic function at the surface of tumor cells alleviates their immunosuppressive activity. Cancer Immunol Res 3: 254-265.

69. Blay J, White TD, Hoskin DW (1997) The extracellular fluid of solid carcinomas contains immunosuppressive concentrations of adenosine. Cancer Res 57: 2602-2605.

70. Bonnefoy N, Bastid J, Alberici G, Bensussan A, Eliaou J-F (2015) CD39: A complementary target to immune checkpoints to counteract tumor-mediated immunosuppression. Oncoimmunology 4: e1003015-e1003015.

71. Moon EK, Wang LC, Dolfi DV, Wilson CB, Ranganathan R (2014) Multifactorial T-cell hypofunction that is reversible can limit the efficacy of chimeric antigen receptortransduced human T cells in solid tumors. Clin Cancer Res 20: 4262-4273.

72. Srivastava MK, Sinha P, Clements VK, Rodriguez P, Ostrand-Rosenberg S (2010) Myeloid-derived suppressor cells inhibit T-cell activation by depleting cystine and cysteine. Cancer Research 70: 68-77.

73. Hart KM, Byrne KT, Molloy MJ, Usherwood EM, Berwin B (2011) IL-10 immunomodulation of myeloid cells regulates a murine model of ovarian cancer Frontiers in Immunology 2: 29-29.

74. Holmgaard RB, Zamarin D, Li Y, Gasmi B, Munn DH (2015) Tumor-Expressed IDO recruits and activates MDSCs in a Treg-Dependent Manner. Cell Rep 13: 412-24.

75. Cherkassky L, Morello A, Villena-Vargas J, Feng Y, Dimitrov DS (2016) Human CAR T cells with cell-intrinsic PD-1 checkpoint blockade resist tumor-mediated inhibition. J Clin Invest 126: 3130-3144.

76. Lu Y, Huang M, Deng T, Zhou X, Yu K (2018) Abstract CT133: A phase I trial of PD-1 deficient engineered T cells with CRISPR/Cas9 in patients with advanced non-small cell lung cancer with PD-L1 expression. Cancer Research 78: CT133.

77. Henick BS, Herbst RS, Goldberg SB (2014) The PD-1 pathway as a therapeutic target to overcome immune escape mechanisms in cancer. Expert Opin Ther Targets 18 1407-1420. [Crossref] 
78. John LB, Devaud C, Duong CP, Yong CS, Beavis PA (2013) Anti-PD-1 antibody therapy potently enhances the eradication of established tumors by gene-modified $\mathrm{T}$ cells. Clin Cancer Res 19: 5636-5646.

79. Liu X, Ranganathan R, Jiang S (2016) A Chimeric Switch-Receptor targeting PD1 augments the efficacy of second-generation CAR T cells in advanced solid tumors. Cancer Res 76: 1578-1590.

80. Rosewell Shaw A, Porter CE, Watanabe N (2017) Adenovirotherapy delivering cytokine and checkpoint inhibitor augments CAR T cells against metastatic head and neck cancer. Mol Ther 25: 2440-2451. [Crossref]

81. Serganova I, Moroz E, Cohen I, Moroz M, Mane M, Zurita J (2016) Enhancement of PSMA-Directed CAR adoptive immunotherapy by PD-1/PD-L1 blockade. Mol Ther Oncolytics 4: 41-54.

82. Gargett T, Yu W, Dotti G, Yvon ES (2016) GD2-specific CAR T cells undergo potent activation and deletion following antigen encounter but can be protected from activation-induced cell death by PD-1 blockade. Mol Ther 24: 1135-1149.

83. Li S, Siriwon N, Zhang X, Yang S, Jin T (2017) Enhanced cancer immunotherapy by chimeric antigen receptor-modified $\mathrm{T}$ cells engineered to secrete checkpoint inhibitors. Clin Cancer Res 23: 6982-6992.

84. ClinicalTrials.gov (2019) CD19-specific CAR-T Cells in CLL/SLL and DLBCL (Registry ID: NCT03960840). Novartis Pharmaceuticals.

85. Dolnikov A, Xu N, Tse B, O'Brien T (2018) Epigenetic agent modulates tumour microenvironment and potentiates cart cell therapy. Cytotherapy 20: S97.

86. Dolnikov A, Yang S, Shen S, Xu N, Chaudhry K (2016) Prolonging CART cell persistence using conditioning with 5-Azacytidine. Cytotherapy 18: S98.

87. Fraietta JA, Beckwith KA, Patel PR, Ruella M, Zheng Z (2016) Ibrutinib enhances chimeric antigen receptor T-cell engraftment and efficacy in leukemia. Blood 127: $1117-1127$.

88. Ramakrishnan R, Huang C, Cho HI, Lloyd M, Johnson J (2012) Autophagy induced by conventional chemotherapy mediates tumor cell sensitivity to immunotherapy. Cancer Res 72: 5483-5493.

89. Turtle CJ, Hay KA, Hanafi LA, Li D, Cherian S (2017) Durable molecular remissions in chronic lymphocytic leukemia treated with CD19-Specific chimeric antigen receptormodified T cells after failure of ibrutinib. J Clin Oncol 35: 3010-3020.

90. Ohtani H, Orskov AD, Helbo AS, Gillberg L, Liu M (2020) Activation of a subset of evolutionarily young transposable elements and innate immunity are linked to clinical responses to 5-azacytidine. cancer research. Canres 2019: 1696.

91. Knox T, Sahakian E, Banik D, Hadley M, Palmer E (2019) Selective HDAC6 inhibitors improve anti-PD-1 immune checkpoint blockade therapy by decreasing the antiinflammatory phenotype of macrophages and down-regulation of immunosuppressive proteins in tumor cells. Sci Rep 9: 6136.

92. Banik D, Moufarrij S, Villagra A (2019) Immunoepigenetics combination therapies: An overview of the role of HDACS in cancer immunotherapy. International Journal of Molecular Sciences 20: 2241
93. van den Bijgaart RJE, Kroesen M, Wassink M, Brok IC (2019) Combined sialic acid and histone deacetylase (HDAC) inhibitor treatment up-regulates the neuroblastoma antigen GD2. J Biol Chem 294: 4437-4449.

94. Chen N, Morello A, Tano Z, Adusumilli PS (2016) CAR T-cell intrinsic PD-1 checkpoin blockade: A two-in-one approach for solid tumor immunotherapy. Oncoimmunology 6: e1273302.

95. Chauvin JM, Pagliano O, Fourcade J, Sun Z, Wang H (2015) TIGIT and PD-1 impair tumor antigen-specific CD8(+) T cells in melanoma patients. J Clin Invest 125: 20462058.

96. Michaud M, Xie X, Bravo-San Pedro JM, Zitvogel L (2014) An autophagy-dependent anticancer immune response determines the efficacy of melanoma chemotherapy. Oncoimmunology 3: e944047.

97. Rosenberg SA, Dudley ME (2009) Adoptive cell therapy for the treatment of patients with metastatic melanoma. Curr Opin Immunol 21: 233-240.

98. Li AM, Hucks GE, Dinofia AM, Seif AE, Teachey DT (2018) Checkpoint inhibitor augment CD19-directed Chimeric Antigen Receptor (CAR) T cell therapy in relapsed B-Cell acute lymphoblastic leukemia. Blood 132: 556-556.

99. Heczey A, Louis CU, Savoldo B, Dakhova O, Durett A, Grilley (2017) CAR T Cells administered in combination with lymphodepletion and PD-1 inhibition to patients with neuroblastoma. Mol Ther 25: 2214-2224.

100. Zhang P, Zhao S, Wu C, Li J, Li Z (20188) Effects of CSF1R-targeted chimeric antigen receptor-modified NK92MI \& $\mathrm{T}$ cells on tumor-associated macrophages. Immunotherapy 10: 935-949.

101. Sachdeva M, Duchateau P, Depil S, Poirot L, Valton J (2019) Granulocyte-macrophage colony-stimulating factor inactivation in CAR T-cells prevents monocyte-dependent release of key cytokine release syndrome mediators. J Biol Chem 294: 5430-5437.

102. Sterner RM, Sakemura R, Cox MJ, Yang N, Khadka RH (2019) GM-CSF inhibition reduces cytokine release syndrome and neuroinflammation but enhances CAR-T cell function in xenografts. Blood 133: 697-709.

103. Boroughs AC, Larson RC, Choi BD, Bouffard AA, Riley LS (2019) Chimeric antigen receptor costimulation domains modulate human regulatory $\mathrm{T}$ cell function. $J C I$ Insight 4 .

104. Lynn RC, Matsuyama T, Powell DJ (2015) Targeting FR $\beta+$ tumor associated macrophages with car $\mathrm{T}$ cells in ovarian cancer. Journal for Immunotherapy of Cancer 3: 32-32.

105. Sakemura R, Cox MJ, Hansen MJ, Hefazi M, Manriquez Roman C, Schick KJ (2019) Targeting cancer associated fibroblasts in the bone marrow prevents resistance to chimeric antigen receptor T Cell therapy in multiple myeloma. Blood 134: 865-865.

106. Di S, Zhou M, Pan Z, Sun R, Chen M (2019) Combined Adjuvant of Poly I:C Improves antitumor effects of CAR-T Cells. Frontiers in Oncology 9: 241-241.

107. Cervantes EV, Boucher JC, Lee SB, Spitler K, Reid K (2019) MDSC Suppression of CAR T cells can be reduced by targeted signaling disruption. Blood 134: 44384438 .

Copyright: (C2020 Tang T. This is an open-access article distributed under the terms of the Creative Commons Attribution License, which permits unrestricted use, distribution, and reproduction in any medium, provided the original author and source are credited. 